\title{
Клинично наблюдение за ефективността на тонзилотрен при 30 пациенти след онзилектомия и аденотонзилектомия
}

\author{
Д. Марев., П. Недев, Г. Илиев, М. Милков \\ УМБАЛ „Света Марина“ ЕАД, Варна, България
}

\begin{abstract}
Резюме:
Острите и хронични тонзилити са едни от най-често срещаните заболявания при хората. За лечението им се използват широка гама от антибиотици, антихистаминови препарати, обезболяващи, гаргари, локални шпрейове. Целта на настоящето съобщение е да се проучи постоперативното възстановяване след тонзилектомия и аденотонзилектомия от лекарството тонзилотрен, приложено самостоятелно при 30 пациенти. По-конкретно, ние изследвахме въздействието на медикамента тонзилотрен след тонзилектомия и аденотонзилектомия при деца до 12 год. и над 12 год. Установи се отчетливо подобряване и скъсяване на следоперативния период на възстановяване. Ефектьт от лечението с тонзилотрен е много по-голям при болните, които не са третирани предварително с други медикаменти. Тонзилотрен има много добри показатели по отношение на безвредност и поносимост.
\end{abstract}

Ключови думи: тонзилектомия, аденоидектомия, тонзилотрен

\footnotetext{
Absract

The acute and chronic tonsillitis are one of the most frequently ENT diseases. The goal of this study is to explore tosilotren impact pre and postoperative by 30 patients (children 12 ear old and older) who were provided tosillectomy with $\backslash$ without adenoidectomy. Treatment with Tonzillotren results in decreased postoperative period. The impact of the treatment is much greater in patients not previously treated with other medications. In conclusion Tonzillotren has very good performance in terms of safety and tolerability.
}

Keywords: tonsillectomy, adenoidectomy, Tonzillotren

\section{Въведение}

Хроничният тонзилит и аденоидит е едно от найчесто срещаните заболявания в клиничната практика. Физиологично уголемяване на лимфоидния гърлен пръстен започва обикновено към 3-4 годишна възраст. Това уголемяване се изразява в индивидуално различната хиперплазия на целия лимфоиден гърлен пръстен, която обхваща особено небните сливици (1-4). При фарингеалната тонзила се среща главно хиперплазия, докато при небните тонзили хиперплазията в повечето случаи е свързана с хронично възпаление. Хроничния тонзилит може да се прояви с десквамация на епитела, с паракератози, ръбци, малки ретенционни кисти, малки хронични абсцеси и цикатризирани паратонзиларни сраствания с околната тъкан. На лимфоидния гърлен пръстен се приписва защитна роля против нахлуващата инфекция в организма (5-6). Сливиците притежават резорбиращи свойства, които през епитела си пропускат вредните корпускуларни частици и бактерии, където се унищожават в лимфните фоликули от фагоцитите, белите кръвни телца и хистиоцитите (7). По литературни данни герминативните центрове са едновременно и реактивни центрове, в които не само се образуват бели крьвни телца, но същевременно става и унищожаването на бактериите, които проникват в организма (8-9). Вирусните инфекции на горните дихателни пътища, макро- и микроклимата, начин на живот, хранене битови и производствени условия могат 
да доведат до изменения на вътрешната среда и нарушения в ЦНС, те стават входна врата на инфекция и метатонзиларни усложнения (10). Увреждането на тонзилите се манифестира чрез различни клинични симптоми. Според Американската академия по оториноларингология и хирургия на главата и шията, симптоматиката при аденотонзилектомия се групира по следния начин:

- Големи клинични симптоми - болка (силна, слаба, липсва), локални усложнения (шйини л. възли, тризмус, хеморагия) (11).

- Малки клинични симптоми - температура, лош дъх, налепи (покрита оперативна рана, частично отпадане, пълно отпадане), гранулация на оперативната рана (12).

- В случай, че клиничните симптоми продължават повече от 7-14 дни, този период се приема за вторична вирусна или бактериална инфекция (13).

От патофизиологична гледна точка вторичната инфекция се характеризира със смущение в евакуацията са слузта и налепите покриваща тонзиларните ложи, в резултат на началната вирусна инфекция, с последващо, включване на факторите движещи възпалителния процес и подтискане на локално действащите защитни сили (14-15).

\section{Клинична ефективност на медикамента тонзилотрен}

Тонзилотрен е хомеопатичен лекарствен продукт. Той е комбинация от пет отделни хомеопатични средства подходящи за лечение на въ3паления на лимфните жлези, фарингити, остри ангини, а също така и при оперативно отстраняване на сливиците (тонзилектомия). Atropinum sulfuricum има положителен ефект при начални температурни фази, които включват зачервено гърло, оточни сливици и болки при преглъщане (16). Останалите четири компонента на тонзилотрен се допълват взаимно при лечението на подострите и хронични случаи, придружени с формиране на мукус (слуз), упоритите и повтарящи остри болки в ушите (17). Silicea ускорява оздравителния процес и намалява податливостта към инфекции, чрез стимулиране на имунната система (18). Тонзилотрен, благодарение на синергичния си ефект, осигурен от петте активни съставки осигурява ефективност през всички фази на на възпалението (19).

\section{За какво се използва тонзилотрен?}

За лечение на остри и хронични рецидивиращи тонзилити, увеличаване на тонзилите в детската възраст и лечение след хирургично отстраняване на сливиците (20).

\section{Противопоказания за примане на тонзилотрен}

Да не се прилага при хора с известна сврьхчувствителност към хром или друга от съставките на продукта.

Да не се използува от пациенти с хиперфункция на щитовидната жлеза,без предварителна консултация с лекар (21).

\section{Специални предупреждения:}

1 таблетка тонзилотрен съдържа 122,50 mg лактоза монохидрат, който е неподходящ с лактозна недостатъчност, галактоземия (галактозен синдром на малабсорбция).

Повремена бременност и кърмене,тонзилотрен трябва да се приема само след консултация с лекар.

\section{Как се използва тонзилотрен?}

Възрастни: При остри състояния се приемат по 1-2 таблетки на интервал от 1 час до максимум 12 таблетки дневно, а при хронични тонзилити по 2 таблетки 3 пъти дневно.

\section{Деца до 12 години:}

При остри състояния по 1 таблетка на 2 часа до максимум 8 таблетки дневно и при хронични тонзилити се приемат по 1 таблетка 3 пъти дневно.

Таблетите тонзилотрен се приемат половин час преди или след хранене и разтопят в устата.

\section{Нежелани лекарствени реакции}

В отделни случаи може да се получи увеличаване на слюноотделянето след приемане на Тонзилотрен.

В редки случаи може да възникнат реакции на свръхчувствителност, като кожни реакции. Съществуващите оплаквания могат временно да се влошат, когато се приемат хомеопатични лекарства. 


\section{Материал и методи}

Общо 30 пациенти от мъжки и женски пол на средна възраст 15 години бяха включени в постмаркетингово рандомизирано клинично проучване след аденотонзилектомия и тонзилектомия. Всички имаха симптоми на хроничен тонзилит, аденоидит и данни за метатонзиларни усложнения.

Тонзилотрен таблети (производител: Deutsche Homoopathie-Union, Germany) бяха приемани от деца до 12 год. след операция първите 2 дни по 1 табл. до 8 на ден през 2 часа и от 3 до 10 ден по 1-2 табл. 3 пъти на ден. При другите болни над 12 години, пьрвите 2 дни по 1 табл. На всеки час до 12 на ден и от 3 до 10 ден по 2 табл./3 пъти на ден, през устата, 30 минути преди храна или след хранене, в продължение на 10 дни.
Главна цел на настоящето наблюдение беше да се определени въздействието на Тонзилотрен върху аденотонзилектомирани и тонзилектомирани болни.

В началото на лечението с тонзилотрен, т.е. 2-ри ден до 8 табл. на ден при деца до 12 год., а при пациенти над 12 год. до 12 табл. и от 3-ти до 10-ти ден, за същата възрастова група по 2 табл. 3 пъти на ден. Динамиката в изявата на симптомите, както и по времето на контролните прегледи щателно документирани и стриктно се следеше за появата на неблагоприятни ефекти при всяка визита на пациентите. От 30 пациенти, отговарящи на необходимите критерии, 2/3 бяха от мъжки пол, което се вижда на таблица 1.

Таблица 1

\begin{tabular}{|c|c|c|c|c|c|c|c|c|}
\hline \multirow{2}{*}{ Пол } & \multicolumn{6}{|c|}{ Възрастови групи } & \multirow{2}{*}{ Общо } & \multirow{2}{*}{$\%$} \\
\hline & $0-4 r$ & $\%$ & 4-15 r & $\%$ & $15-36$ г & $\%$ & & \\
\hline Мъже & 3 & 60 & 10 & 47.6 & 1 & 25 & 14 & 46.7 \\
\hline Жени & 2 & 40 & 11 & 52.4 & 3 & 75 & 16 & 53.3 \\
\hline Общо & 5 & 16.7 & 21 & 70.0 & 4 & 13.3 & 30 & 100 \\
\hline
\end{tabular}

На таблица 2 е показано възрастовото разпределение на изследваните от нас пациенти. Средната възраст е 20 години.

Таблица 2

\begin{tabular}{|l|c|}
\hline \multicolumn{1}{|c|}{ Възраст } & Години \\
\hline Средна & 20 \\
\hline Минимална & 4 \\
\hline Максимална & 36 \\
\hline
\end{tabular}

На таблица 3 е показано постоперативното възстановяване. Средно тя е 7 дни.

Таблица 3

\begin{tabular}{|l|c|}
\hline Постоперативно възстановяване & Дни \\
\hline Средно & 7 \\
\hline Минимално & 5 \\
\hline Максимално & 10 \\
\hline
\end{tabular}

\section{Статистическа обработка на резултатите от наблюдението}

При повечето пациенти се установява, че имаме скъсяване на следоперативното възстановяване на аденотонзилектомирани и тонзилектомирани болни (22). Най-често се наблюдаваше по-рано отпадане на налепите и гранулиране на оперативната рана. Тези данни бяха потвърдени чрез контролни прегледи на оперираните болни ,което беше направено на всички 30 пациенти на 3-ия, 7-ия, 14-ия ден от клиничното наблюдение.

По време на първоначалния преглед пациентите показваха различна степен на развитие на заболяването (таблица 4)

Таблица 4

\begin{tabular}{|l|c|r|}
\hline \multicolumn{1}{|c|}{ Симптоми ден 3 } & Брой болни & Процент \\
\hline Главоболие & 4 & $13.3 \%$ \\
\hline Болки в гърлото & 30 & $100 \%$ \\
\hline Неприятен дъх от устата & 25 & $83.3 \%$ \\
\hline Шиини лимфни възли & 10 & $33.3 \%$ \\
\hline Тризмус & 5 & $16.7 \%$ \\
\hline Температура & 15 & $50 \%$ \\
\hline Отпадналост & 13 & $43.3 \%$ \\
\hline Умора & 24 & $80 \%$ \\
\hline Кашлица & 1 & $3.3 \%$ \\
\hline следоперативни налепи & 30 & $100 \%$ \\
\hline Оток на увулата & 15 & $50 \%$ \\
\hline Поставяне на система & 10 & $33.3 \%$ \\
\hline $\begin{array}{l}\text { Болезненост при натиск в } \\
\text { областта на шията }\end{array}$ & 23 & $76.7 \%$ \\
\hline
\end{tabular}


След 7-дневно лечение с тонзилотрен повечето от наблюдаваните клинични симптоми бяха отстранени. Някои от тях, като хранене,температура, налепи, болка в гьрлото, оток на увулата персистираха, но в по-лека форма и при по-мальк брой болни (таблица 5).

Таблица 5

\begin{tabular}{|l|c|c|}
\hline \multicolumn{1}{|c|}{ Симптоми ден 7 } & $\begin{array}{c}\text { Брой } \\
\text { болни }\end{array}$ & Процент \\
\hline Хранене & 1 & $2,04 \%$ \\
\hline Болки в гърлото & 4 & $8,16 \%$ \\
\hline Налепи по ложите & 10 & $33,3 \%$ \\
\hline Оток на увулата & 3 & $6,12 \%$ \\
\hline Температура & 3 & $6.12 \%$ \\
\hline
\end{tabular}

На 14-ия ден от клиничното проучване след спиране на лечението с тонзилотрен тези симптоми не се наблюдаваха. От всички 30 изследвани пациенти 20-има бяха лекувани единствено с тонзилотрен. Останалите 10 (33.3\%) пациенти получаваха допълнителни медикаменти, включващи антибиотик и нестероиден противовъзпалителен препарат.

За обработката на данните от клиничните симптоми, за статистически модел се приложи анализ на променливите при многократни замервания (АНОВА). Установи се значителна линейна промяна $(\mathrm{p}<0,002)$ при перцепцията за болка и гранулиране на оперативната рана в лечението с Тонзилотрен. Включването на продължителността на следоперативното възстановяване показа, че зависимостта между деня на операцията и продължителността на възстановяването след нея също е значителна $(p=0,023)$ и има линейна тенденция (23). Само по себе си влиянието на продължителността на възстановяването, включено като основен параметьр в модела не показа значими статистически резултати $(\mathrm{P}=$ 0,357) (24). Статистическият метод потвърди, че допълнителното медикаментозно лечение няма статистически значимо влияние върху времето на възстановяване.

Впечатляващо е, че отпадането на налепите и гранулиране на оперативната рана при всички пациенти, се осьществи в съкратено време до появата на нормално усещане в гърлото, независимо от използваните съпьтстващи медикаменти при лечението с тонзилотрен (25). Ние установихме, че разликата във времето на изменение на постоперативното възстановяване между 7-я и 14-я ден от началото на лечението е същест- вена. Може да се твърди обаче, че позитивният ефект от проведеното 10-дневно лечение с тонзилотрен се поддържа и дори се подобрява през целия контролен период.

Посредством фарингоскопско изследване проведено по време на 1-я преглед се установи наличие на налепи (100\%), обикновено съчетано с хиперемия, оток на лигавицата. Контролните прегледи, направени на 7-я и 14-я ден от началото на лечението с Тонзилотрен, показаха достоверно редуциране на налепите до пълно отпадане и снижение в степента на оплаквания на болните. По този начин обективно се потвърди ефективността на приложеното лечение с Тонзилотрен върху гранулирането и постоперативното възстановяване (26).

Тонзилотрен е медикамент с отличителни показатели за безвредност и поносимост, което бе доказано по безспорен начин, тъй като по време на клиничното наблюдение не бяха отчетени никакви странични реакции и взаимодействия.

\section{Заключение}

Настоящото клинично наблюдение показа по безспорен начин, че лекарственото средство тонзилотрен е ефикасно по отношение подобряването и следоперативно възстановяване на аденотонзилектомирани и тонзилектомирани болнина при изследваните от нас пациенти с остьр и хроничен тонзилит. Наблюдаваните от нас болни показват, че с течение на времето имаме отчетливо подобрение в средното време на оперираните болни. Като се има предвид, че налепите и гранулационния период, е най-важният протективен механизъм на постоперативното възстановяване, несъмнено е, че този доказан ефект на медикамента Тонзилотрен е много благоприятен за клиничния ход на острите и хроничните тонзилити.

Голям брой от нашите пациенти бяха лекувани предварително с няколко антибиотика. Това ни даде възможност на сравним ефекта от лечението с тонзилотрен и ние установихме, че той е много по-голям при болните, които не са лекувани предварително с други медикаменти. От това следва важният за клиничната практика извод, че когато се определя първоначалната терапевтична схема трябва да се има предвид благоприятния ефект на тонзилотрен върху 
постоперативното възстановяване,в сравнение със случаите без употреба на тонзилотрен.

Позитивният ефект от 7-дневното лечение с Тонзилотрен се задържа и дори се подобрява през целия контролен период от 14 дни. В заключение искаме да подчертаем, че медик-

\section{Литература:}

1. Pichichero, M.E. et al.: Outcomes after judicious antibiotic use for respiratory tract infections seen in a private pediatric practice. PEDIATRICS 105, 4: 753-759 (2000)

2. Koch, K.: Warum Ärzte gegen Viren mit Antibiotika vorgehen. Therapieentscheidungen wider besseres Wissen. Dt. Ärzteblatt 96, 27: C 1320 - C 1321 (1999)

3. N.N.: Missbrauch von Antibiotika. Z. Chemotherapie 21, 9/10; 33 34 (2000)

4. del Mar, C.: Sore throat and antibiotics. Applying evidence on small effects is hard, variations are probably inevitable. BMJ 320: 130-131 (2000)

5. Becker, S., Kunstmann, K. D. Angina tonsillaris - Erfolgreiche Behandlung mit einem homöopathischen Kombinationsarzneimittel Ärztezeitschrift für Naturheilverfahren 5, 36: 372-377 (1995)

6. Boenninghaus, H. G. Hals-Nasen-Ohrenheilkunde Springer Verlag, Berlin Heidelberg New York (1996)

7. B. M. Blochin, A. Bokowoi, M. Heger, B. Schützle Wirksamkeit und Verträglichkeit eines homöopathischen Präparates bei akuter Angina catarrhalis im Kindesalter. Publikation in Vorbereitung (1999)

9. Del Mar, Ch. Managing Sore Throat: A Literature review. Med. J. Australia 156, 4: 644-649 (1992)

10. Feinstein, A. R.Friese, K. H. Homöopathie in der HNO-Heilkunde Hippokrates Verlag, Stuttgart (1994)

11. Friese, K. H.Homöopathische Therapie akuter Halsentzündungen Therapiewoche 44: 328-334 (1994)

12. Gastanaduy, A. X., Kaplan, E. L.Failure of Penicillin to Eradicate Group A Streptococci During an Outbreak of Pharyngitis.Lancet 2, 498 (1980)

13. Ginsburg, C. M.A Controlled Comparative Study of Penicillin V and Cefadroxil Therapy of Group A Streptococci Tonsillopharyngitis.J. Int. Med. Res. 8, Suppl. 1, 82 (1982)

14. Heusser, P.Prüfkriterien zur Beurteilung des Nutzens von komple mentärmedizinischen Methoden. Anhang II für die Teilnehmer des Workshops in Bern vom 18. Dezember 1997. ментът тонзилотрен притежава много добри показатели за безвредност и поносимост. Това ни дава основание да го препоръчаме като една добра възможност при определяне на лечението на острите и хроничните тонзилити.

15. Kiene, H.A Critique of the double blind clinical trial: part I Alternative Therapies in Health \& Medicine 2, 1: 14-80 (1996)

16. Kori-Lindner, C.Arzneimittelprüfung: Empfehlung der Gesellschaft für Phytotherapie (GPHY). Zur Planung, Durchführung und Auswertung von Anwendungsbeobachtungen.FÄPI-intern !: 13-16 (1997)

17. Linde, K., Melchart, D., Weidehammer, W.Randomisierte klinische Studien in der Komplementärmedizin - Mehr Schaden als Nutzen?Forschende Komplementärmedizin 4: 169-173

18. Mezger, J.Gesichtete homöopathische ArzneimittellehreHaug Verlag, Heidelberg (1993)

19. Milatovic, D.Cephadroxil versus Penicillin bei der Behandlung der A-Streptokokken Tonsillopharyngitis. Eur. J. Clin. Microbiol. Infect. Dis. 8, 4 (1989)

20. Nohr, H. Der "grippale Infekt" und das Tonsiotren. Aus unserer Arbeit. Mitteilung aus Forschung und Praxis 4, 1: 29-30 (1965)

21. Dr. W. Schwabe GmbH, Karlsruhe Röhlke, H. W. Zur Behandlung der entzündeten und hypertrophen Tonsillen besonders im Kindesalter.Erfahrungsheilkunde 17, 9: 333-336 (1968)

22. Schwartz, R., Weintzen, R., et al.Randomized Trial of 7 vs. 10 Days of Penicillin V Therapy for Group A Streptococcal Pharyngitis. Pediatric Res. 14, 517 (1980)

23. Stillerman, M., Isenberg, H.Streptococcal Pharyngitis Therapy: Comparison of Cyclacillin, Cephalexin and Potassium Penicillin V. Antimicrob. Agents. Chemotherapy 10, 270-276, (1970)

24. Stillerman, M., Isenberg, H.Streptococcal Pharyngitis Therapy: Comparison of Cephalexin, Phenoxymethylpenicillin and Ampicillin. Am. J. Dis. Child. 123, 457 (1972)

25. Stirn, A. Erfahrungen mit Tonsiotren in der werksärztlichen Praxis Die Medizinische 11: 392-393 (1957)

26. Walenz, H.Über die Erfahrung mit Tonsiotren in der kinderärztlichen Praxis. Kinderärztliche Praxis 22, 10 (1954) 